\title{
SUBSÍDIOS PARA A FORMULAÇÃO DE POLÍTICAS PÚBLICAS DE JUVENTUDE NO BRASIL'
}

Luiz Antonio Cruz Caruso ${ }^{2}$

Anne Caroline Posthuma ${ }^{3}$

\section{INTRODUÇÃO}

A crise financeira de 2008 provocou um aumento significativo da taxa de desemprego dos jovens entre os países da Organização para a Cooperação e o Desenvolvimento Econômico - OCDE (ONU, 2018). Atualmente, entre os mais de 1 bilhão de jovens no mundo (cerca de 16\% da população mundial), muitos estão desempregados, encontram-se em trabalhos precários e informais e, mesmo entre aqueles que se encontram empregados, uma quantidade muito grande vive em condiçóes de pobreza (ILO, 2017). Superar essa situação exige esforços crescentes dos países e, com vistas a suplantar esses e outros problemas, a Cúpula das Naçóes Unidas sobre o Desenvolvimento Sustentável, em setembro de 2015, elaborou um documento contendo dezessete Objetivos de Desenvolvimento Sustentável (ODS), entre os quais destacamos os três mais diretamente voltados para os jovens: ODS 8.5; ODS 8.6; e ODS 8.b. ${ }^{4}$

$\mathrm{Na}$ sociedade moderna, a juventude representa um período da vida em que muitas transiçóes ocorrem simultaneamente, sendo as principais a da adolescência para a vida adulta e a da escola para o trabalho (Guimarães et al., 2018). Nesse período, o jovem constrói sua identidade pessoal e profissional, por meio de muitas tentativas para estabelecer relaçóes pessoais, de educação e de trabalho.

As condiçóes de integração à sociedade dos/das jovens variam, de uma época a outra, em função das oportunidades, das dificuldades, das facilidades e do poder que possuem, de modo suas expectativas se transformam ao longo do tempo. O foco das políticas de juventude esteve condicionado pelas situaçóes sociais e culturais de cada período histórico. Até os anos 1990, por exemplo, como a condição juvenil era vista como problemática em si mesma, as políticas foram desenhadas, em sua maioria, para enfrentar problemas da juventude. Nos anos 2000, com o avanço da redemocratização da sociedade, do fortalecimento dos movimentos sociais em geral, e dos jovens em particular, assim como dos programas promovidos por organismos internacionais, as políticas públicas passaram a entender a juventude como uma etapa do ciclo

1. DOI: http://dx.doi.org/10.38116/bmt70/dossiea3

2. Consultor da Organização das Nações Unidas para a Educação, a Ciência e a Cultura (UNESCO).

3. Diretora do Centro Interamericano para el Desarrollo del Conocimiento en la Formacion Profesional (CINTERFOR) da Organização Internacional do Trabalho (OIT).

4. Ver: <https://bit.ly/3okG8lq>. 
da vida que carrega sentido em si mesma (Silva e Silva, 2011). A agenda de política pública voltada para a juventude ganhou força no Brasil a partir da implementação da Política Nacional de Juventude, em 2005.

O objetivo desse artigo é o de identificar as principais características das políticas públicas de juventude, nacionais e internacionais, no período de 2006 a 2019, e fornecer subsídios para a formulação de políticas de juventude. $\mathrm{Na}$ seção 2, serão caracterizadas as heterogeneidades. Na seção 3, destacaremos as principais políticas nacionais no período de 2005 até os dias atuais e as políticas de juventude mais citadas na bibliografia internacional. Por fim, na seção 4, serão feitas considerações para a formulação de políticas de juventude.

\section{HETEROGENEIDADE NAS TRANSIÇÕES DA ESCOLA PARA O TRABALHO}

Esta seção tem o propósito de explicitar que as transiçôes da escola para o mundo do trabalho são múltiplas e heterogêneas, e fortemente dependentes de cor, sexo ou condição socioeconômica dos jovens, entre outros marcadores sociais. Baseamo-nos em estudos, elaborados entre 2014 e 2018, a partir dos resultados da pesquisa realizada no âmbito do Projeto "Work4Youth", fruto de uma parceria entre a Organização Internacional do Trabalho (OIT) e a Fundação MasterCard, envolvendo a participação de 28 países, recobrindo o período de 2006 a 2013. Essa pesquisa explorou, em profundidade, as diversas transiçóes da escola para o trabalho dos jovens brasileiros, possibilitando perceber e mapear a extrema diversidade de expectativas e escolhas que os jovens utilizaram naquele período. Escolhemos esse recorte por possibilitar caracterizar melhor a heterogeneidade presente nas transiçóes escola-trabalho dos jovens.

\subsection{Fatores estruturais presentes nas transições da escola para o mundo de trabalho}

No período de 2006 a 2013, ocorreu uma melhoria da escolaridade dos jovens em termos da quantidade de anos de estudo, bem como da proporção de jovens que concluíram o ensino médio ou o superior. As maiores diferenças em termos de anos de estudo adquiridos aparecem ao se comparar os jovens por renda (cinco anos de diferença na faixa etária 25-29, no quintil de renda mais alta comparativamente ao quintil de renda mais baixa). Além disso, a proporção de jovens com ensino superior completo cresceu de forma mais intensa para os jovens de renda mais alta (Costa, 2015).

Ao mesmo tempo, no período de 2006 a 2013, ocorreu uma queda na parcela de jovens ocupados, que pode ser explicada pela redução na taxa de participação. Como ocorreu um aumento na escolaridade média, pode-se supor, inicialmente, que os jovens permaneceram mais tempo na escola, particularmente os jovens entre 15 e 17 anos (Corseuil e Franca, 2015). Quando se compara os indicadores de mercado de trabalho por nível de renda, observa-se que existe uma piora nos indicadores de taxa de ocupação, participação e desemprego, conforme a renda se reduz. $\mathrm{O}$ mesmo ocorre quando se compara esses mesmos indicadores por gênero, com uma piora significativa para as pessoas do sexo feminino em comparação às pessoas do sexo masculino. O desemprego dos jovens, ainda que tenha se reduzido entre 2006 e 2013, permaneceu em um patamar bastante elevado e é tanto maior quanto menor a idade (Corseuil e Franca, 2015). 
Entre 2006 e 2013, aumentou a quantidade de jovens que busca conciliar suas experiências laborais com escolarização, profissionalização e vida familiar. As jovens que têm filhos precocemente tendem a ter maiores dificuldades para fazer essa conciliação. Os jovens de 15 a 17 anos também possuem forte propensão a conciliar trabalho e estudo, ainda que a situação de jovens, particularmente do sexo feminino, que nem trabalham, nem estudam (nem-nem) continue muito elevada. A proporção de jovens que deixam seus filhos em creches aumenta de acordo com a faixa etária, com o gênero - mais mulheres deixam seus filhos em creches, do que homens -, e com a renda - quanto maior a renda, maior é o acesso a creches (Silva, Macedo e Figueiredo, 2015).

Diagnósticos recentes (Venturi e Torini, 2014; Guimarães, Marteleto e Brito, 2018) identificam que a maior parte das atuais transiçóes da escola para o trabalho ocorre de forma não linear. Tais diagnósticos revelam que é cada vez menor a proporção de jovens que passam pelo percurso tradicional de se inserirem no mundo do trabalho logo após terem concluído a fase escolar. Guimarães, Marteleto e Brito (2018) concluem que existem diversas transiçóes (educacionais, demográficas e laborais) que influenciam heterogêneas trajetórias juvenis que marcam a passagem à vida adulta e a forma da sua relação com o mundo do trabalho. $\mathrm{O}$ estudo conclui, também, que a maioria da juventude brasileira precisa conciliar os estudos com o trabalho, sendo que os chamados jovens nem-nem apresentam maiores dificuldades de conciliar essas diferentes demandas, especialmente as mulheres jovens. Para Venturi e Torini (2014), "a transição para o mercado de trabalho é definida como a passagem de uma pessoa jovem (entre 15 e 29 anos) ao fim da sua vida escolar (ou entrada na primeira atividade econômica) até o primeiro emprego estável ou satisfatório".

Desses estudos, se conclui também que as transiçóes da escola para o trabalho de maior sucesso foram associadas mais frequentemente com os jovens do sexo masculino, de maior nível educacional, de renda familiar mais elevada e que residem numa área urbana.

\subsection{Situação dos jovens durante a pandemia}

A pandemia da Covid-19 encontrou o mercado de trabalho com uma recuperaçáo lenta, o que comprometeu ainda mais a inserçáo dos jovens. Além disso, o sistema educacional interrompeu suas atividades e de forma muito lenta as atividades escolares foram retornando, de forma remota, primeiro na rede privada e posteriormente na rede pública de ensino. Como o acesso à internet é precário para uma parte significativa dos jovens que frequentam a rede pública, o aprendizado escolar no ano de 2020 está sendo seriamente comprometido (Cepal, 2020).

Comparando as taxas de desemprego dos jovens no período 2015-2017 com as do período 2019-2020, ambos períodos recessivos, verificamos que são muito próximas. Contudo, como argumentou Corseuil (2020), enquanto em 2015-2017 os jovens encontravam muita dificuldade de sair do desemprego e, por conseguinte, aumentava o desemprego de longa duração, em 2019 e, particularmente, nos meses da pandemia até maio de 2020, de acordo com a Pesquisa Nacional por Amostra de Domicílios (PNAD) Covid-19, caíram as taxas de desemprego. Isso decorreu do fato de que aumentou a taxa de jovens fora da força de trabalho, 
tanto para o jovem que estava ocupado no mercado formal quanto no informal, ou mesmo no desemprego. Segundo Corseuil (2020), "essa desconexão com o mercado de trabalho aumenta a preocupação com a trajetória futura dos jovens".

Considerar a enorme diversidade nos percursos que os jovens realizam entre escola e trabalho, é de suma importância para subsidiar o desenho de uma política de juventude focalizada em grupos de jovens. Caso contrário, as desigualdades sociais e econômicas tenderão a se acentuar no futuro, sendo que esse quadro pode ser ainda mais agravado pela pandemia.

\section{POLÍTICAS DE JUVENTUDE}

Um dos maiores desafios que as políticas de juventude enfrentam é fazer com que os jovens possam ingressar no mercado de trabalho seja obtendo um emprego formal ou criando e gerindo seu próprio negócio. A educação geral e a formação profissional são os principais instrumentos de política utilizados para viabilizar essa inserção e, boa parte dos esforços se traduz em ampliar grau de correspondência entre as qualificaçôes adquiridas pelos jovens e as características das vagas oferecidas no mercado de trabalho. Esses dois fatores - inserção laboral e educação costumam estar associados na maioria das políticas de juventude e procuraremos entender como evoluíram recentemente e se é possível apreender alguma tendência nessa evolução. Começaremos com a perspectiva internacional para, em seguida, abordar as políticas nacionais.

\subsection{Políticas de juventude: perspectiva internacional}

Majoritariamente as políticas de juventude atuam pelo lado da oferta, principalmente por meio de programas de educaçáo básica e profissional. A partir dessa perspectiva, emerge a discussão sobre a relevância do sistema educacional, entendida como sua capacidade de prover indivíduos através das qualificaçôes que possam ser aplicadas em contextos educacionais, carreira profissional e na esfera cívica, ao longo de suas vidas. Um conjunto de condiçóes favorece a relevância dos sistemas educacionais, a partir de uma base comum identificada em diferentes países que parte da articulação sistemática entre provedores de educação geral e profissional e empregadores.

Na prática, a aproximação do sistema educacional com o sistema produtivo pode ser feita de inúmeras formas, sendo que, a maioria, possui forte inspiração no modelo dual alemão os denominados modelos de formação por alternância, em que a parte teórica da formaçáo é realizada na escola e a parte prática na empresa. Esses modelos vêm sendo crescentemente utilizados por diversos países, com vistas a reduzir defasagens entre as qualificaçôes detidas pelos jovens e as requeridas pelas empresas, bem como para diminuir o tempo de transiçáo entre a escola e o trabalho. Do ponto de vista das instituiçóes de formaçáo profissional, uma das principais razóes para a utilização crescente dos modelos de formação por alternância é a velocidade com que o progresso técnico é incorporado ao sistema produtivo, que tornou praticamente impossível para as instituiçóes de formação profissional incorporarem tal progresso, no mesmo ritmo, em suas oficinas e laboratórios. Na perspectiva dos jovens, sua falta de experiência é uma barreira para a transição escola-empresa e isso é minimizado pelos modelos 
por alternância. As principais formas utilizadas para aproximar a empresa da escola ocorrem quando os empregadores participam mais ativamente do desenvolvimento de currículos e da capacitação de jovens em programas de aprendizagem, treinamento e estágio, entre outros. Ao mesmo tempo, os sistemas de educação e de educação profissional necessitam ser mais dirigidos pelas demandas do setor produtivo e flexíveis para captar e desenvolver qualificaçóes requeridas pela incorporação de novas tecnologias e processos ao sistema produtivo, particularmente às tecnologias vinculadas à transformação digital.

O reconhecimento da heterogeneidade nas transiçóes escola-trabalho está presente em boa parte das políticas de juventude de diversos países. Verifica-se a existência de programas de complementação de escolaridade, programas para jovens que abandonam a escola antes da conclusão do curso e educaçáo de jovens e adultos associados ou náo a programas de educação profissional. Quando a questão principal é a falta de experiencia profissional, as soluções baseadas em alternância, como a aprendizagem no local de trabalho ou programas que possuem a supervisão de profissionais qualificados no local de trabalho (estágio, trainee etc.) podem ser bastante eficazes (Kluve et al., 2017).

Como para os jovens a obtenção de conhecimentos pela educação geral, educação profissional e experiência profissional é permanente e não ocorre em um único momento no tempo, muitos países desenvolveram mecanismos de certificaçáo de conhecimentos e de competências. Isso facilita as passagens entre os diferentes campos de aprendizagem da escola ou da empresa, reconhecendo a acumulaçáo dos saberes obtidos, o que é crescentemente aceito por educadores e empregadores. Também se está tendo um crescente reconhecimento pelo conceito de aprendizagem ao longo da vida.

Quando se trata de apoiar jovens para começar seus próprios negócios, a maioria dos países oferece programas que combinam atividades de capacitação profissional (preparar plano de negócios, registro em livro caixa, entre outras), acesso a financiamento (microcrédito, empréstimo etc.), informaçóes sobre o mercado, mentoria e coaching. Um caso interessante de empreendedorismo é o Programa Calificación de Jóvenes Creadores de Microempresas, do Peru. A avaliação, realizada por Jaramillo e Parodi (2003), apontou um impacto positivo na criaçáo de empregos e na probabilidade de o negócio sobreviver por mais de um ano, tendo sido, o acesso ao crédito, o principal fator que impulsionou o impacto do programa.

Como a inserção no mercado de trabalho é uma variável fortemente dependente da conjuntura econômica, subsídios a empregos e salários são utilizados para facilitar essa inserção. $\mathrm{O}$ estímulo à contratação de jovens, por meio principalmente da redução do custo de contratação, é um mecanismo bastante utilizado. Contudo, o sucesso dessa política depende da focalização dos grupos que se quer atingir, sob pena de se incorrer em efeitos de substituição (a empresa demite um trabalhador não subsidiado e o substitui por um trabalhador subsidiado). Também são bastante utilizados programas públicos de emprego e criação de oportunidades de emprego temporário em trabalhos públicos tradicionais (manutenção de estradas, conservação do meio ambiente, entre outros). 
$\mathrm{Na}$ América Latina e Caribe os programas voltados para os jovens frequentemente percorrem quatro grandes eixos: capacitação, empreendedorismo, serviços e subsídios. O modelo básico de intervenção identificado na região visa aumentar as chances do jovem se inserir no mercado formal de trabalho, possivelmente, porque na regiáo latino-americana predomina um elevado desemprego dos jovens e um imenso mercado informal, que absorve a maioria dos mesmos. Existem, também, algumas intervençóes voltadas para ampliar o empreendedorismo dos jovens. Muitos programas foram direcionados para jovens desempregados e em situaçáo de vulnerabilidade, sendo que o modelo básico de intervenção identificado se repete em vários países com pequenas variações: capacitação seguida de estágio em empresa. O modelo básico surge da implementação desse tipo de política a partir dos anos 1990 e foi sendo aprimorado com base na experiencia dos países. Parte do pressuposto que faltam experiencia laboral e conhecimentos técnicos e, posteriormente, foi diagnosticada a necessidade de oferecer capacitação soft skills.

A Comunidade Europeia tem lançado várias iniciativas para ajudar os jovens, com ênfase nos serviços e apoios para ajudar o retorno à escola, formaçáo e contato com o mercado de trabalho. Vale mencionar alguns programas, como a Iniciativa de Oportunidades para Juventude (de 2012 a 2013) e a Estratégia de Jovens da União Europeia (de 2010 a 2018). Uma iniciativa que tem chamado atenção pela sua conceituaçáo, viés integrativo e impacto é o Garantia Jovem (GJ), formulado para enfrentar os desafios de desemprego juvenil com intervençóes rápidas e atendimento personalizado, provendo ativaçáo ao curto prazo e uma inserção em oportunidades de emprego ou educação/formação profissional (Eurofound, 2015). Uma dimensão fundamental do GJ é sua proatividade e o engajamento com o público jovem, provendo "ofertas de educaçáo continuada" dentro de um conjunto de medidas que visam trazer jovens com baixos níveis de escolaridade e qualificaçóes de volta para os estudos e/ou se formar. Assim, o GJ oferece aos jovens (de até 25 anos de idade) oferta de emprego de qualidade, ensino continuado, oportunidade de aprendizagem ou estágio por um período após ter saído do ensino formal ou de ter se tornado desempregado. O GJ foi formulado para enfrentar três desafios: $i$ ) desemprego juvenil de longo prazo; ii) segmentaçáo no mercado de trabalho, que frequentemente leva a uma sobre representaçáo de jovens em empregos temporários ou em meio-período; e iii) desempenho limitado de sistemas de educação e formação profissional, que leva ao descompasso entre as competências dos jovens e as demandas do mercado de trabalho. O serviço público de emprego em cada país é um ator chave na implementaçáo eficaz do GJ, envolvendo uma ampla gama de intervençóes associadas a uma abordagem mais holística de serviços, orientaçáo de carreira e provisão de serviços diretos de emprego (EC, 2018).

As avaliaçôes de impacto de políticas de juventude revelam que os programas existentes para enfrentar os desafios do emprego dos jovens se concentram do lado da oferta, sendo que alguns temas aparecem com frequência, entre os quais, destacamos: a oferta precisa atender à demanda; a identificação de forma apropriada dos grupos-alvo (focalizaçáo); a formaçáo é mais efetiva quando se tem interação com o mundo do trabalho (modelos de formação por alternância); a associação entre formação e colocação de emprego (Namita et al., 2018; Kluve et al., 2016; Escudero et al., 2017). 
Além disso, a assimetria de informaçóes é uma questão que afeta tanto o jovem - que não sabe identificar e comunicar corretamente suas próprias competências e não reconhece com clareza se atende ao que é exigido pela empresa - quanto à própria empresa - que tem dificuldade em reconhecer as competências do candidato e, por vezes, de comunicar corretamente as competências da própria vaga. Associar aos programas de formação uma etapa de intermediação, contendo orientação para preencher um currículo, como se comportar durante uma entrevista de emprego, entre outros conteúdos vem se mostrando extremamente eficaz. Os sistemas de informação sobre o mercado de trabalho evoluíram muito nos últimos anos e são capazes de auxiliar, de forma significativa, tanto os candidatos a emprego como os ofertantes de vagas. Na Índia, em um mesmo espaço físico, com o auxílio de um especialista ou diretamente via internet, o candidato preenche seu currículo, se candidata a uma vaga e, caso seja identificada alguma lacuna de competências, é indicada a instituição de educação profissional que oferece cursos que podem suprir essa lacuna. Esse mesmo modelo existe no Canadá, o chamado Eletronic Labor Exchange, que possibilita buscar e candidatar-se a uma vaga de emprego, e o próprio sistema identifica eventuais mismatchings entre as competências possuídas pelo candidato e as requeridas pela vaga e indica a instituição de formaçáo profissional onde pode obter as competências faltantes.

Em síntese, os serviços de emprego, que procuram fazer uma ligação entre a oferta e a demanda, estão concentrando um conjunto de atividades, que incluem: Serviços de Orientação Profissional; informaçóes sobre oportunidades no mercado de trabalho e planejamento de carreira; assistência à procura de emprego; preparação de curriculos; preenchimento de formulários de candidatura a emprego; feiras de emprego para auxiliar empregadores a preencher vagas; e associação com outras políticas, principalmente com as de treinamento e formação profissional.

As metodologias de avaliação de impacto foram evoluindo com a implementação desses programas e vieram se tornando, gradualmente, mais acuradas, exigindo um maior volume de recursos. Ao mesmo tempo, os resultados das avaliaçóes indicam invariavelmente a necessidade de ampliação do esforço de planejamento do programa, melhorando o foco no público alvo e na implementaçáo do programa, com acompanhamento e correçóes de rumo mais constantes.

A experiência internacional revela que a articulação de políticas de oferta e demanda resulta, em geral, em resultados mais significativos, do que a atuação isolada de uma política. Em síntese, a inserção laboral aumenta quando: a capacitação está alinhada com as necessidades das empresas; os jovens têm apoio de serviços de emprego; os jovens sáo acompanhados por um período mais longo de tempo, para eles saírem de uma situação mais estrutural (tutorias sociolaborais). Por exemplo, no Programa Peruano de Treinamento de Jovens Para o Emprego (em espanhol, Programa de Capacitación Laboral Juvenil - Projoven), as empresas que iriam absorver os alunos para estágio foram selecionadas previamente e o programa de treinamento foi desenhado entre as instituiçóes de formaçáo profissional e essas empresas. Os jovens que participaram do programa foram monitorados por um período após a realização do estágio e receberam apoio dos serviços de emprego. 


\subsection{Políticas de juventude no Brasil (recentes)}

Um marco extremamente importante na história de políticas de juventude no Brasil ocorreu em 2005, com a promulgação da Política Nacional de Juventude. Em um curto espaço de tempo, tomando por base o Guia de Políticas Públicas de Juventude, editado em 2006, foi desenhado um amplo conjunto de programas e projetos voltados para os jovens, como: Escola de Fábrica, Juventude e Meio Ambiente, Integração de Educação Profissional ao Ensino Médio na Modalidade de Educação de Jovens e Adultos (Proeja), Estímulo ao Primeiro Emprego (PNPE), Programa Nacional de Fortalecimento da Agricultura Familiar (Pronaf) Jovem, Universidade para Todos (ProUni), entre outros. Essas iniciativas estavam voltadas para aumento da escolaridade ou reinserção escolar, inserção no mercado de trabalho, estímulo a atividades nas áreas de esportes, cultura e meio ambiente. Uma interação virtuosa entre especialistas no tema, pressōes de movimentos sociais ligados aos jovens, sob a coordenação da Secretaria Nacional de Juventude propiciou a rápida expansão e articulação dessas políticas.

Atualmente, o Ministério da Economia está preocupado com a transformação digital, tanto pela crescente demanda por competências digitais como pelo uso das plataformas digitais para a oferta do ensino. Considerando-se que muitas atividades possam vir a ser reduzidas, modificadas ou mesmo desaparecer, e ao mesmo tempo muitas oportunidades surgirão, especialmente no campo da tecnologia de informação, vem surgindo a necessidade de fortalecer as "competências digitais" entre jovens. Desse modo, uma das açôes que a Secretaria Nacional da Juventude deflagrou foi a oferta de cursos de tecnologia da informação (TI) em uma plataforma Microsoft. O Ministério da Economia desenvolveu, também, o Programa Emergencial de Manutenção do Emprego e da Renda, visando à preservação do emprego por meio de acordos individuais ou coletivos entre trabalhadores e empregadores nas situações de: redução proporcional de jornada de trabalho e de salário e suspensão temporária do contrato de trabalho. A área de Educação Profissional e Tecnológica do Ministério da Educação e Cultura criou um protocolo de biossegurança para garantir a segurança sanitária de servidores e alunos, nos espaços comuns, quando do retorno às atividades presenciais e está monitorando o funcionamento dos Institutos e das Universidades Federais. Além disso, estão garantindo o acesso à internet a cerca de 900 mil alunos da rede federal em situação de vulnerabilidade socioeconômica; ampliando a capacidade de salas de webconferências, com potencial de beneficiar 123 mil alunos dos Institutos Federais e da Plataforma para Cursos Massivos online (Mooc). A Secretaria Nacional de Juventude está desenvolvendo um modelo de gestão colaborativa para articular políticas de juventude por meio do estímulo à comunicação vertical (com a juventude) e horizontal (entre diferentes ministérios).

No caso brasileiro, além da necessidade de melhorar a focalização do público alvo nas políticas, é urgente melhorar a qualidade da educação básica. Ao longo dos últimos 25 anos, ao mesmo tempo que se ampliou muito o acesso da população jovem à educação básica, a qualidade do ensino, medida em termos de proficiência em português e matemática, caiu. As medidas indicam uma piora progressiva da proficiência à medida que o aluno conclui o ensino fundamental 1, o fundamental 2 e o ensino médio, tanto em português como em matemática. $\mathrm{O}$ abandono e a repetência dos estudantes agravam esse quadro. Os problemas, 
extensamente diagnosticados, encontram-se no campo da valorização dos profissionais de ensino, gestão escolar, currículo e infraestrutura. $\mathrm{O}$ ensino médio, que apresenta elevada taxa de abandono e repetência, aponta o ensino superior como o único caminho para o jovem prosseguir seus estudos e se inserir no mercado de trabalho, o que contrasta visivelmente com todas as experiencias internacionais de países desenvolvidos e em desenvolvimento. Ao mesmo tempo, o país fez, em 2017, a Reforma do Ensino Médio, diversificando as opções e criando um itinerário formativo associado à educaçáo técnica. Esses novos itinerários representam um grande desafio e oportunidade.

\section{CONSIDERAÇÕES FINAIS}

No atual contexto político e econômico do país, uma política de juventude deveria estar inscrita em uma perspectiva de inserçáo dos jovens no mercado de trabalho em postos de trabalho de maior produtividade.

Do ponto de vista da demanda, chama a atenção o fato da produtividade do trabalho encontrar-se estagnada há mais de vinte anos. Entre os fatores que explicam essa estagnação destaca-se a estrutura ocupacional possuir elevada proporção de trabalhadores de baixa qualificação (mais de 70\%) e manter constante tal proporção durante todo esse período. Mudar a estrutura ocupacional passa pela mudança nos padróes de competição, incorporação de novas tecnologias e mapeamento de processos e, tudo indica que a promoção de incentivos poderia estimular as empresas a modificarem suas estruturas ocupacionais. A codificação de conhecimentos, pela via de mapeamento de processos e incorporação de novas tecnologias, facilitaria a contratação de técnicos de nível médio e profissionais de nível superior. Esse tema é relevante pois com a implementação da Reforma do Ensino Médio tenderá a ocorrer uma expansão da oferta de jovens técnicos de nível médio e, se a demanda por esses profissionais não se ampliar, a inserção profissional não trará ganhos significativos na produtividade.

Do ponto de vista da oferta, as experiencias nacional e internacional reconhecem que os jovens apresentam transiçóes escola-trabalho heterogêneas, irregulares, incertas e que nem sempre conduzem a resultados satisfatórios. Após essa constatação, as políticas de juventude passaram, crescentemente, a focalizar em grupos específicos de jovens. Além disso, observando a experiencia internacional, percebemos que uma forte tendência para a integração de políticas, sendo que o que varia é a estratégia de integração. Uma primeira estratégia apresenta um menor grau de interação com jovens. Por exemplo: cursos de formação profissional são mais eficazes quando associados a serviços de intermediação; sistemas de informação sobre mercado de trabalho são mais eficazes quando identificam as vagas, comparam as exigências da vaga com o perfil do jovem, verificam se faltam conhecimentos e competências, indicam a instituição de formação que pode suprir essas lacunas e completam o encaminhamento. Esse serviço pode ser on-line (Canadá) ou presencial (Índia). A segunda estratégia é mais interativa e pode alcançar a personalização do atendimento aos jovens. $\mathrm{Na}$ mesma agência, o jovem pode avaliar suas expectativas, conhecimentos e habilidades, escolher um curso, receber orientação laboral e para a preparaçáo do seu currículo ou ser encaminhado para uma vaga de emprego. A partir 
do primeiro atendimento, passa a ser acompanhado por um determinado período, até se encaixar em alguma atividade, escolar ou de trabalho. Esse é o modelo do GJ, com o formato implementado por Portugal.

Os estudos de transição para o caso brasileiro evidenciaram as heterogeneidades nos percursos dos jovens entre a escola e o trabalho. Ao estilizarmos os fatos revelados por esses estudos, verificamos que um grupo mais restrito de jovens seguem seus estudos até o final e entram no mercado de trabalho, sendo que esses jovens são, em sua maioria, brancos, do sexo masculino, oriundos de famílias com renda per capita elevada e residentes em áreas urbanas. Outro grupo de jovens, que apresenta grandes proporçóes, abandonou precocemente os estudos para se inserir no mercado de trabalho ou para cuidar de filhos e poucos destes retornaram à escola. São em sua maioria meninas e meninos negros, pertencentes a famílias de faixa de renda mais baixa, moradores das periferias ou em comunidades dos grandes centros. Evidentemente, esse segundo grupo apresenta marcas e desafios sociais que se reproduzem historicamente e as políticas de juventude devem tê-lo como foco prioritário. Porém, esse grupo é, em si, muito diverso. A jovem adolescente que engravidou e abandonou a escola necessita de suporte distinto do jovem que saiu da escola para trabalhar. Esses jovens fazem inúmeras tentativas para reentrar na escola ou no mercado de trabalho, algumas vezes com sucesso, mas muitas vezes sem lograr êxito, o que gera frustração, desalento e baixa autoestima. Jovens nem-nem são hoje uma parcela crescente em nossa sociedade, sendo este grupo extremamente heterogêneo e vulnerável, requerendo um marco de políticas que contemple essas realidades e necessidades sociais, educacionais e vocacionais para superar as barreiras e promover sua maior inserção social, laboral e econômica.

A experiencia brasileira com a formulação de políticas de juventude desde 2005 revelou a importância de se ter um órgão de coordenação de diferentes iniciativas que, no nosso caso, foi a Secretaria Nacional de Juventude. O fato em si revela que já existia a percepção das heterogeneidades nas transiçôes escola-trabalho e a necessidade de se traçar diferentes políticas. Um esforço necessita ser feito em relação à focalização das políticas em grupos específicos de jovens. Além disso, do ponto de vista operacional, as estratégias de integração de políticas, mencionadas anteriormente, poderiam ser implementadas sem grandes investimentos. Exigiriam um esforço de coordenação e de desenho de políticas e a implementação poderia ficar sob responsabilidade das agências do Sistema Nacional de Emprego ou dos Centros de Referência de Assistência Social (Cras), que apresentam enorme capilaridade geográfica. Nessas agências, os responsáveis pelo atendimento aos jovens deveriam passar por uma capacitação para poderem absorver novas competências para identificar as necessidades de cada jovem, fazer o encaminhamento adequado e acompanhar, por um período de tempo, os resultados.

\section{REFERÊNCIAS}

CEPAL - COMISSÃO ECONÔMICA PARA AMÉRICA LATINA E O CARIBE. Universalizar o acesso às tecnologias digitais para enfrentar os impactos da COVID-19. Santiago: CEPAL, 2020. 
CORSEUIL, C. H.; FOGUEL, M. N.; GONZAGA, G. Apprenticeship as a stepping stone to better jobs: Evidence from Brazilian matched employer-employee data. Labour Economics, v. 57, p. 177-194, 2019.

CORSEUIL, C. H.; POLOPONSKY, K.; FRANCA, M. P. Diagnóstico da inserção dos jovens brasileiros no mercado de trabalho em um contexto de crise e maior flexibilizaçáo. Brasília: OIT; Ipea, 2020.

CORSEUIL, C. H.; FRANCA, M. A. P. Inserçáo dos jovens no mercado de trabalho brasileiro: evolução e desigualdades no período 2006-2013. 1. Ed. Brasília: OIT; Ipea, 2015. COSTA, J. Educação dos jovens brasileiros no período 2006-2013. Brasília: OIT; Ipea, 2015. EC - EUROPEAN COMMISSION. Study on the youth guarantee in light of changes in the world of work. Bruxelas: COM, 2018.

ESCUDERO, V. et al. Active Labour Market Programmes in Latin America and the Caribbean: evidence from a meta analysis. Bonn: IZA, set. 2017. p. 1-43. (Discussion Paper).

EUROFOUND - FUNDAÇÃO EUROPEIA PARA A MELHORIA DAS CONDIÇÓES DE VIDA E DE TRABALHO. Beyond the youth guarantee: lessons learned in the first year of implementation. Luxembourg: Eurofound, 2015.

GUIMARÃES, N. A.; MARTELETO, L; BRITO, M. M. A. Transiçóes e trajetórias juvenis no mercado brasileiro de trabalho: padróes e determinantes. Brasília: OIT, dez. 2018.

ILO - INTERNATIONAL LABOUR OFFICE. Global employment trends for youth 2017: paths to a better working future. Geneva: ILO, 2017.

KLUVE, J. A review of the effectiveness of active labour market programmes with a focus on Latin America and the Caribbean. International Labour Office, 2016.

KLUVE, J. et al. Do Youth Employment Programs Improve Labor Market Outcomes? A Systematic Review. Germany: IZA, 2016.

KLUVE, J. et al. Interventions to improve the labour market outcomes of youth: a systematic review. A Campbell Systematic Review, v. 10, n. 1, 2017.

ONU - ORGANIZAÇÃO DAS NAÇÃO UNIDAS. World youth report: youth and the 2030 agenda for sustainable development. New York: UN, 2018.

SILVA, R. S.; SILVA V. R. Política Nacional de Juventude: trajetória e desafios. Caderno CRH, Salvador, v. 24, n. 63, p. 663-678, 2011.

SILVA, E. R. A.; MACEDO, D. M. B.; FIGUEIREDO, M. M. A. Conciliação dos estudos, trabalho e vida familiar na juventude brasileira. Brasília: OIT; Ipea, 2015.

VENTURI, G.; TORINI, D. Transiçóes da escola para o trabalho dos jovens homens e mulheres no Brasil. Genebra: OIT, dez. 2014. (Working Paper, n. 25). 


\section{BIBLIOGRAFIA COMPLEMENTAR}

BARDAK, U.; MASEDA, M. R.; ROSSO F. Young people not in employment, education or training (NEET): an overview of ETF Partner Countries. Turin: European Training Foundation, 2015. Disponível em: <https://bit.ly/33WK3CM>.

BRASIL. Secretaria Geral da Presidência da República. Guia de Políticas Públicas de Juventude. Brasília: SGPR, 2006.

- Secretaria Geral da Presidência da República. Secretaria Nacional de Juventude. Secretaria de Políticas de Promoção da Igualdade Racial. Plano Juventude VIVA: caminhos da política de prevenção à violência contra a juventude negra no Brasil. Brasília: SGPR; Seppir, [s.d.].

. Ministério do Trabalho e Emprego. Agenda nacional de trabalho decente para a juventude. Brasília: MTE, 2011.

- Secretaria de Governo da Presidência da República. Secretaria Nacional de Juventude.

Caderno de orientaçóes para formalizaçáo e execuçáo do programa estaçáo juventude PEJ. Brasília: Segov; SNJ, 2017.

Secretaria de Planejamento e Assuntos Econômicos. Estratégia nacional de desenvolvimento econômico e social. Brasília: Seplan; IBGE; Ipea; BNDES, 2019.

Senado Federal. Estatuto da Juventude: atos internacionais e normas correlatas. Brasília: Coordenação de Ediçóes Técnicas, 2013.

EC - EUROPEAN COMMISSION. An EU strategy for youth: Investing and empowering - A renewed open method of coordination to address youth challenges and opportunities. Bruxelas: COM, 2009.

. Youth employment initiative. Strasbourg: COM, 2013.

. Employment and social developments in Europe. [s.l.]: COM, 2017.

. Youth guarantee \& youth employment initiative. [s.1.]: COM, 2019a. Disponível em: <https://bit.ly/2GWOiFW>.

New data show more than 14 million young people benefitted from youth guarantee. [s.1.]: COM, 2019b.

Youth guarantee $\&$ youth employment initiative. [s.1.]: COM, 2019c.

Two new studies focus on the implementation of the youth guarantee and the role of public employment services. [s.l.]: COM, 2019d. Disponível em: <https://bit. ly/2H1MCe6>.

ECA - EUROPEAN COURT OF AUDITORS. Youth unemployment: have EU policies made a difference? Luxemburgo: ECA, 2017.

GONZAGA, G. Avaliação do suplemento da PNAD 2014: educação profissional. Brasília: SENAI; Departamento Nacional, 2015.

HUTCHINSON, J.; BECK, V.; HOOLEY, T. Delivering NEET policy packages? A decade of NEET policy in England. Journal of Education and Work, v. 29, n. 6, p. 707-727, 2016. 
IBARRARÁN, P. et al. Experimental evidence on the long-term impacts of a youth training pro. Germany: IZA, jun. 2015. (Working Paper, n. 9136).

MAGUIRE, S. NEET, unemployed, inactive or unknown - why does it matter? Educational Research, v. 57, n. 2, p. 121-132, 2015.

O'HIGGINS, N. Rising to the youth employment challenge: new evidence on key policy issues. International Labour Organization. 2017.

ONU - ORGANIZAÇÃO DAS NAÇÃO UNIDAS. Transformando nosso mundo: a agenda 2030 para o desenvolvimento sustentável. [s.l.]: UN, 2015.

SILVA, E. R. A. et al. A informalidade do trabalho da juventude no brasil: o que pensam os/as integrantes do Subcomitê da Agenda Nacional de Trabalho Decente para a Juventude. Brasília: OIT; Ipea, 2015.

SPARREBOOM, T.; STANEVA, A. Is education the solution to decent work for youth in developing economies? Identifying qualifications mismatch from 28 school-to-work transition surveys. Geneva: ILO, Dec. 2014.

SPOSITO, M. P.; GALVÃO, I. A experiência e as percepçôes de jovens na vida escolar na encruzilhada das aprendizagens: o conhecimento, a indisciplina, a violência. Perspectiva, Florianópolis, v. 22, n. 2, p. 345-380, jul./dez. 2004. 
